\title{
Exploring the relationship of sleep quality with drug use and substance abuse among university students: a cross-cultural study
}

\author{
Fahmi Hassan Fadhel ${ }^{1,2}$ (D)
}

\begin{abstract}
Background: There is a growing interest in studying the area of drugs and college students due to the negative effects that drugs have on a student's social life, academics, psychology, finances, and health. So, this study aims to identify the relationship between drug/substance abuse and quality of sleep among university students in Yemen and Saudi Arabia. The sample size was $935(43.21 \% N=404$ female, 56.79\% $N=531$ male, 55.40\% N = 518 Yemeni, and 44.60\% N= 417 Saudi). Students responded to the Drug Abuse Screening Test (DAST-10), the Pittsburgh Sleep Quality Index (PSQI), and the Substance Abuse Questionnaire.

Results: The results showed a high prevalence of drug use: $43.1 \%$ of respondents (27.27\% $N=219$ Yemenis and 15.83\% $N=148$ Saudis) abuse drugs, $29.41 \%$ were in the low level of drug use, $10.48 \%$ were in the moderate level of drug use, $2.46 \%$ were in the substantial level of drug, and $0.75 \%$ were in the severe level of drug use as per the DAST-10. The differences between both countries in terms of drug use were significant $\left(X^{2} 19.394, P<0.001\right)$. The prevalence rate of inhalants was $16.36 \%$ and of sedatives was $12.09 \%$, and the differences between countries were significant. The prevalence of poor sleep quality was $24.81 \%$; a total of $7.91 \%$ of respondents had very poor sleep quality, while $16.90 \%$ had poor sleep quality. The differences between countries were not significant.

The relationship between sleep quality and drug use, smoking, and substance abuse was significant. The quality of sleep decreased consistently with a high level of drug use or substance abuse.
\end{abstract}

Conclusions: Poor sleep quality is significantly associated with drug use and substance abuse, and it is important to recognize the factors affecting drug and substance abuse among university students. A significant contribution can make for the protection of university students by guaranteeing that psychological interventions for high-risk groups are planned in advance.

Keywords: Sleep quality, College students, Drug use, Substance abuse

\section{Background}

Drug and substance abuse is widespread among students [1-4]. In every country, students misuse a variety of substances; they smoke tobacco (including cigarettes and water pipes, or narghile and shisha, as they are called in the Middle East), chew tobacco, inhale volatile substances (solvents such as glue and gasoline), use sedatives such as diazepam

\footnotetext{
Correspondence: fahmi4n@yahoo.com; ffadhel@kku.edu.sa

${ }^{1}$ Psychology Department, College of Education, King Khalid University, Abha, Saudi Arabia

${ }^{2}$ Faculty of Arts, Hodeidah University, Hodeidah, Yemen
}

(a benzodiazepine), take hypnotics such as amphetamines, and cannabis, or take drugs such as cocaine and heroin.

Each country has its own specific culture in terms of the use of certain types of drugs or the misuse of specific substances. For example, people in Yemen talk about the prevalence of diazepam abuse among young adults who chew khat [5]. While diazepam is a sedative, taking it with khat has an invigorating effect, leading to increased stimulation and a sense of euphoria, vitality, and activity in the individual.

The growing interest in studying drugs among college students stems from the negative effects that drugs can have on a student's social life, academics, psychology,

\section{Springer Open}

(c) The Author(s). 2020 Open Access This article is licensed under a Creative Commons Attribution 4.0 International License, which permits use, sharing, adaptation, distribution and reproduction in any medium or format, as long as you give appropriate credit to the original author(s) and the source, provide a link to the Creative Commons licence, and indicate if changes were made. The images or other third party material in this article are included in the article's Creative Commons licence, unless indicated otherwise in a credit line to the material. If material is not included in the article's Creative Commons licence and your intended use is not permitted by statutory regulation or exceeds the permitted use, you will need to obtain permission directly from the copyright holder. To view a copy of this licence, visit http://creativecommons.org/licenses/by/4.0/. 
finances, and health. Studies have shown that drugs affect an individual's physical and psychological health [6, 7], while drug addiction can lead to mental disorder or affect consciousness, memory, sleep and wake disorders, and concentration. Indeed, there are researchers who assert that cognitive impairments are inevitable consequences of drug abuse in the long run, appearing as a major deficit in many cognitive areas such as executive functions, memory, attention, and perception [8]. Additionally, drugs negatively affect academic performance and achievement among students [9].

Sleep disturbances, especially poor sleep quality and insomnia, are the most common psychological and clinical problems among a wide range of other issues and mental disorders such as drug and substance abuse [10]. "Sleep disturbance is a primary characteristic of multiple substance use disorder syndromes" [11].

The term poor sleep quality refers to insomnia, and the researchers believe that "insomnia is a common predictor of addiction" [12], as many complaints about sleep difficulties can be linked to addiction. People who are addicted to a substance or a drug complain of sleep problems that make the relationship between drug use and sleep difficulties a bilateral relationship, i.e., each problem may be a cause, and a consequence, of the other $[10,13,14]$. This is because "the neurobiology of sleep and drug use are interconnect[ed]" [14]. When one abstains from drug or substance abuse, sleep disturbances become more severe, which may lead to relapse.

This conclusion was reinforced by the results of studies finding a relationship between insomnia and drug use or addiction [15-17]. Insomnia may predict a return to drug use [18]. Therefore, sleep disturbances may be a direct cause of relapse after recovery from addiction to drugs or other substances. Several studies have found a relationship between sleep disorders, low sleep quality, and relapse of substance abuse $[19,20]$. For example, in addition to the low quality of sleep among caffeine or nicotine addicts [21], recent studies have found a high prevalence of sleep dissatisfaction among sedative abusers [22].

Although the relationship between sleep quality and the use of drugs and substances has been documented $[10,15,17,18,23]$, studies in the Arab world are still few. A review of local research reveals that very few studies have investigated the relationship between sleep quality and drug use or substance abuse among university students in Yemen and Saudi Arabia.

Thus, the current study aims to examine the relationship between drug use or substance abuse and sleep quality among university students in Yemen and Saudi Arabia.

\section{Methods}

\section{Sample}

The study sample consisted of 935 undergraduate students. According to the strategic plan of King Khalid
University 2018-2020 [24], the number of students registered at the university during 2018, at all levels of study (diploma, bachelors, masters, and doctorate) reached 59, 495, distributed over 29 colleges. Meanwhile, the number of students at the University of Aden in the same year was 23,615, distributed over 24 colleges. A random selection was made for 10 colleges, representing 34.48\% of the colleges at King Khalid University and $41.67 \%$ of the colleges at the University of Aden. The research sample was restricted to the first, second, third, and fourth levels, as some of the colleges that were randomly selected include other levels (such as the Faculties of Medicine and Engineering) that are not available in the other colleges, which may have affected the comparison of the results between colleges.

Although the research tools were distributed over the Internet through the university's communications, the sending of tools was limited to undergraduate students in the first 4 years, as most colleges have no more than 4 years of study, unlike the Faculties of Medicine and Engineering, in which the study exceeds 4 years. Thus, there is no parity between the sample members in the variable years of study.

\section{Measures}

The participants answered the following tools:

(a) The Drug Abuse Screening Test (DAST-10) [25] is a self-report test for assessing drug abuse. The brief image consists of 10 items. It has been used in a number of studies and has good psychometric properties. In this study, the reliability coefficient of Cronbach's alpha was 0.780 and the split-half reliability was 0.677 . The Spearman-Brown coefficient equal length was 0.808 . Internal consistency was calculated on the DAST-10, by calculating the correlation between the score for each item and the overall score on the scale. The correlations were good, ranged between 0.53 and 0.64 , and were significant at the 0.05 level.

(b) Substance Abuse Questionnaire (SAQ): The researcher prepared this questionnaire to evaluate substance abuse among university students in Yemen and Saudi Arabia. The questionnaire was prepared after a review of the literature in this field, and the initial version was presented to several mental health professionals at the College of Education, King Khalid University, so that they could assess its authority in evaluating substance abuse among university students. Some items of the questionnaire were reformulated according to the reviewers' notes. 
The questionnaire consisted of 14 items covering the misuse of substances and other psychotropics such as smoking (including cigarettes, narghile, hookah, and chewing tobacco), sedatives (including diazepam), inhalers, and energy drinks.

The SAQ is a validated questionnaire. Cronbach's alpha reliability was 0.703 , and the split-half reliability was 0.552 . The Spearman-Brown coefficient equal length was 0.712 .

The internal consistency of the questionnaire was calculated by the correlation between the item score and the overall score of the SAQ. The correlation ranged between 0.365 and 0.581 and was significant at the 0.05 level.

(c) The Pittsburgh Sleep Quality Index (PSQI) [26] is a self-report measure consisting of nine items for assessing subjective sleep quality and is characterized by good validity and reliability. In this study, Cronbach's alpha reliability was 0.778 , and the splithalf reliability was 0.668 . The Spearman-Brown coefficient equal length was 0.801 .

The DAST-10 and PSQI were translated into Arabic by the current researcher. The Arabic versions were subject to reverse retranslation into English by a language expert, and the proportions of consistency between the original and the backward translation was high: $96.3 \%$ on the DAST-10 and $93.8 \%$ on the PSQI.

In addition, the study collected demographic variables such as age, marital status, academic level, and gradepoint average in the previous semester. The estimated average time taken to answer the scales was $50 \mathrm{~min}$.

\section{Procedures}

The current research was based on an online survey of university students in Yemen and Saudi Arabia. The questionnaire was distributed to students through the Deanship of Student Affairs using the university's communications. The researcher obtained ethical approvals from Aden University (Ref 201/3/311) and King Khalid University (Number 28423). The students were informed at the beginning of the questionnaire that participation in the research was completely voluntary and all students gave expressed written consent.

\section{Statistical analysis}

Statistical analysis was carried out using the Statistical Package of Social Sciences (SPSS-16), using descriptive statistics, cross-tab, Pearson's chi-squared test $\left(\chi^{2}\right)$, independent samples $t$ test, one-way ANOVA, and multiple comparisons, especially the Scheffe test, Pearson correlation coefficient, and Cronbach's alpha.

\section{Results}

A total of $55.40 \%(N=518)$ were Yemeni students from Aden University, while $44.60 \%(N=417)$ were Saudi students from King Khalid University. The percentage of female students was 43.21\% $(N=404)(21.71 \% N=203$ Yemeni and $21.497 \% N=201$ Saudi female students). The participants were distributed among 10 colleges: Medicine, Education, Computer, Arts, Humanities, Sciences, Community, Law, Engineering, and Colleges of Business.

Table 1 shows the demographic characteristics of the research sample.

The age ranged between 18-39years (21.83 SD \pm $2.892)$, with significant differences between students of both countries ( $t$ test $5.629, P<0.000$ ).

The results of this study showed that $56.9 \%(N=532)$ of the students $(28.13 \% N=263$ Yemenis and $28.77 \% N=269$ Saudis) had no problems with drugs, $29.41 \%(N=275)$ of the students $(18.50 \% N=173$ Yemenis and $10.91 \% N=102$ Saudis) were at the low level of the DAST-10, and $10.48 \%$ $(N=98)$ of the students $(6.95 \% N=65$ Yemenis and $3.53 \%$ $N=33$ Saudis) were at the moderate level. Additionally, $2.46 \%(N=23)$ of the students $(1.50 \% N=14$ Yemenis and $0.96 \% N=9$ Saudis) were at the substantial level. The lowest percentage was at the severe level $(0.75 \% N=7)(0.32 \%$ $N=3$ Yemenis and $0.43 \% N=4$ Saudis).

According to these results, there are high rates of drug use among university students, $43.1 \%$ of respondents (27.27\% $N=255$ Yemenis and $15.83 \% N=148$ Saudis) abuse drugs. The differences between students of the two countries were statistically significant $\left(X^{2} 19.394, P\right.$ $<0.001)$. These results are shown in Fig. 1 .

It was found that $12.09 \%$ of respondents $(N=113)$ abuse sedatives $(3.32 \% N=31$ of Yemen and $8.77 \% N=$ 82 of Saudi), and $16.36 \%(N=153)$ of respondents (2.46\% $N=23$ of Yemen and $13.90 \% N=130$ of Saudi) abuse inhalants. The differences between the Yemeni and Saudi students were significant in sedatives $\left(X^{2}\right.$ 40.689, $P<0.00)$ and in inhalants $\left(X^{2} 120.65, P<0.000\right)$. The prevalence of the abuse of sedatives and inhalers was higher among the Saudis.

Our results are found that $7.91 \%$ of respondents (3.74\% $N=35$ of Yemeni and $4.17 \% N=39$ of Saudi students) had very poor sleep quality while $16.90 \%(8.66 \%$ $N=81$ of Yemeni and $8.24 \% N=77$ of Saudi students) had poor sleep quality. A total of $27.70 \%(N=259)$ of respondents $(16.47 \% N=154$ of Yemeni and $11.23 \% N=$ 105 of Saudi students) had very good sleep quality, and a total of $47.49 \%(N=444)$ of respondents $(26.52 \% N=$ 248 of Yemeni and $20.96 \% N=196$ of Saudi students) had good sleep quality. The differences between the two countries were not significant $\left(X^{2} 4.824, P<0.185\right)$.

The relationship between sleep quality and drug use was significant. The Pearson correlation coefficient was 
Table 1 Demographic characteristics of students

\begin{tabular}{|c|c|c|c|c|c|}
\hline \multirow{2}{*}{$\begin{array}{l}\text { Variables } \\
\text { Year of study }\end{array}$} & \multicolumn{2}{|l|}{ Yemen sample } & \multicolumn{2}{|l|}{ Saudi sample } & \multirow{2}{*}{$\begin{array}{l}\text { Total } \\
935\end{array}$} \\
\hline & Frequency $(N=518)$ & Percentage $(55.40 \%)$ & Frequency $(N=417)$ & Percentage $(44.60 \%)$ & \\
\hline First & 147 & 15.72 & 137 & 14.65 & $284(30.37 \%)$ \\
\hline Second & 108 & 11.55 & 28 & 2.99 & $136(14.55 \%)$ \\
\hline Third & 169 & 18.07 & 114 & 12.19 & $283(30.27 \%)$ \\
\hline Fourth & 84 & 8.98 & 138 & 14.76 & 222 (23.74\%) \\
\hline \multicolumn{6}{|l|}{ Sex } \\
\hline Male & 315 & 33.69 & 216 & 23.10 & $531(56.79 \%)$ \\
\hline Female & 203 & 21.71 & 201 & 21.50 & $404(43.21 \%)$ \\
\hline \multicolumn{6}{|l|}{ Marital status } \\
\hline Single & 442 & 47.27 & 385 & 41.18 & $827(88.45 \%)$ \\
\hline Married & 69 & 7.38 & 27 & 2.89 & $96(10.27)$ \\
\hline Divorced/widower & 7 & 0.75 & 5 & 0.53 & $12(1.28 \%)$ \\
\hline \multirow[t]{2}{*}{ Age } & Mean & SD & Mean & SD & 935 \\
\hline & 22.30 & 3.161 & 21.25 & 2.396 & \\
\hline
\end{tabular}

0.0188 and was significant at 0.01 . The $X^{2}$ test also showed significant differences among university students in terms of sleep quality according to the level of drug use in the DAST-10. These results are shown in Table 2.

Table 2 shows a significant relationship between sleep quality and drug use among university students. The quality of sleep decreases consistently with a high level of drug use, i.e., those who use drugs have poor sleep quality.
Also, the relationship between the overall score on the PSQI and drug use (using the total score of the DAST10) was significant. The Pearson correlation was 0.247 and was significant at the 0.01 level. A one-way ANOVA showed the significance of differences in the total PSQI score among university students according to the levels of drug use in the DAST-10 $(F=14.454$, $P<0.000)$.

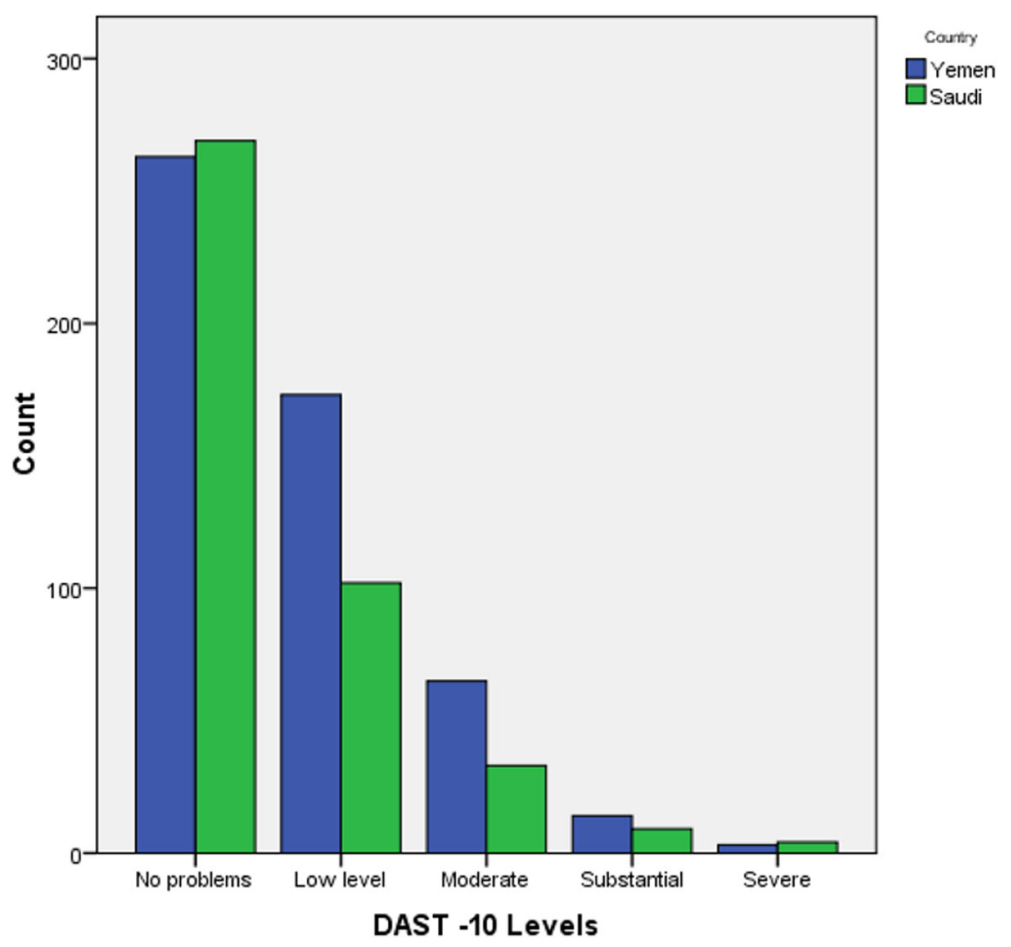

Fig. 1 Prevalence of drug use among Yemeni and Saudi students 
Table 2 Relationship between sleep quality and drug use

\begin{tabular}{|c|c|c|c|c|c|}
\hline \multirow[t]{2}{*}{ Sleep quality } & \multicolumn{5}{|c|}{ Levels of DAST-10 } \\
\hline & No problems & Low level & Moderate & Substantial & Severe \\
\hline Very good & 165 & 71 & 19 & 4 & 0 \\
\hline Good & 256 & 130 & 49 & 6 & 3 \\
\hline Bad & 80 & 55 & 14 & 8 & 1 \\
\hline Very bad & 31 & 19 & 16 & 5 & 3 \\
\hline Total & 532 & 275 & 98 & 23 & 7 \\
\hline \multicolumn{3}{|l|}{$X^{2}=45.984$} & \multicolumn{3}{|l|}{$P=0.000$} \\
\hline \multicolumn{3}{|c|}{ Sleep quality and total score of DAST-10: $R=0.188^{* *}$} & \multicolumn{3}{|l|}{$P=0.000$} \\
\hline \multicolumn{3}{|c|}{ Total of PSQI and total score of DAST-10: $R=0.247^{* *}$} & \multicolumn{3}{|l|}{$P=0.000$} \\
\hline
\end{tabular}

${ }^{* *}$ Correlation is significant at the 0.01 level ( 2 tailed)

The Scheffe test for multiple comparisons was used to detect the differences between groups, as shown in Table 3 .

Table 3 shows significant differences in the overall PSQI score among university students according to the level of drug use in the DAST-10. These differences were indicative between the level of no problems and low level, moderate, substantial, and severe levels, and between low level and substantial levels. The overall PSQI score decreased consistent with a high level of drug use, i.e., those who use drugs have poor sleep quality.

The results of the current study showed a significant relationship between sleep quality, smoking, and substance abuse among university students as shown in Table 4 .

According to Table 4, significant differences emerged in terms of sleep quality between abusers and non-abusers of substances. The quality of sleep was poor in those who misused sedatives, inhalations, chewing tobacco, energy drinks, or soft drinks. These results also showed that whatever the type of smoking, smokers have poor sleep quality as compared to non-smokers, and the differences were statistically significant.

Table 3 Multiple comparisons (Scheffe)

\begin{tabular}{lllll}
\hline Total of PSQI & & & & \\
\hline (I) DAST-10 & (J) DAST-10 & $\begin{array}{l}\text { Mean difference (I- } \\
\text { J) }\end{array}$ & $\begin{array}{l}\text { Std. } \\
\text { error }\end{array}$ & $\begin{array}{l}\boldsymbol{P} \\
\text { value }\end{array}$ \\
\hline No & Low level & $-1.278^{\mathrm{a}}$ & 0.320 & 0.003 \\
problems & Moderate & $-2.244^{\mathrm{a}}$ & 0.473 & 0.000 \\
& Substantial & $-4.354^{\mathrm{a}}$ & 0.917 & 0.000 \\
& Severe level & $-5.795^{\mathrm{a}}$ & 1.638 & 0.014 \\
Low level & Substantial & $-3.076^{\mathrm{a}}$ & 0.934 & 0.029 \\
Moderate & No & $2.244^{\mathrm{a}}$ & 0.473 & 0.000 \\
& problems & & & \\
Substantial & No & $4.354^{\mathrm{a}}$ & 0.917 & 0.000 \\
& problems & & & \\
& Low level & $3.076^{\mathrm{a}}$ & 0.934 & 0.029 \\
\hline
\end{tabular}

${ }^{a}$ The mean difference is significant at the 0.05 level

\section{Discussion}

There are high rates of drug use among university students in Yemen and Saudi Arabia. Over half of the students (56.9\%) were distributed in the first level (no problem) of the DAST-10, and $44.1 \%$ of students stated that they had abused drugs at least once in their lives, which is undoubtedly high. Our results found that approximately one third of those who had problems with drugs were on the second level "the low level."

These students do not need therapeutic interventions as much as they need psychological counseling to avoid the risk of drug addiction. This may be due to university students' awareness of the risks of drug exposure and its negative effects on the individual, the family, and society.

On the other hand, the percentage of students distributed among the dangerous levels in the DAST-10-i.e., the moderate, substantial, and severe levels-was $13.71 \%$. These are high prevalence rate. Significant differences were observed between Yemeni and Saudi students in terms of the prevalence of drug use. Although the proportions of students who had no problems with drugs in both countries were equal, the differences were relatively clear in the other four levels of the DAST-10. Yemeni students had higher prevalence rates than did Saudi students at the low, moderate, and substantial levels, while the prevalence rates at the severe level were relatively close in both countries.

These results indicate an alarming prevalence of drug abuse among university students in Yemen and Saudi Arabia. A significant percentage of the respondents of this study had serious problems with medication and will need psychological intervention.

These results are consistent with those of studies that have found high prevalence rates of drug use among students. For example, Brandt, Taverna, and Hollock [27] reported a high prevalence rate for non-medical use of prescription medications.

Meanwhile, the results of this study differ with the study of Kounenou [28], who found low prevalence rate 
Table 4 Relationship between sleep quality and substance abuse

\begin{tabular}{|c|c|c|c|c|c|c|c|c|c|c|}
\hline \multirow[t]{2}{*}{ Sleep quality } & \multicolumn{4}{|l|}{ Abuser } & \multicolumn{4}{|l|}{ Non-abuser } & \multirow[t]{2}{*}{$x^{2}$} & \multirow[t]{2}{*}{$P$ value } \\
\hline & Very good & Good & Bad & Very bad & Very good & Good & Gad & Very bad & & \\
\hline Sedatives & 14 & 55 & 26 & 18 & 245 & 389 & 132 & 56 & 24.188 & 0.000 \\
\hline Inhalants & 25 & 83 & 27 & 18 & 234 & 361 & 131 & 56 & 13.77 & 0.003 \\
\hline Cigarettes & 14 & 40 & 21 & 21 & 245 & 404 & 137 & 53 & 35.322 & 0.000 \\
\hline Narghile & 6 & 12 & 5 & 7 & 253 & 432 & 153 & 67 & 10.341 & 0.016 \\
\hline Hookah & 6 & 16 & 5 & 8 & 253 & 428 & 153 & 66 & 11.89 & 0.008 \\
\hline Chewing tobacco & 9 & 23 & 11 & 10 & 250 & 421 & 147 & 64 & 11.54 & 0.009 \\
\hline Energy drinks & 8 & 32 & 22 & 18 & 251 & 412 & 136 & 56 & 40.26 & 0.000 \\
\hline Soft drinks & 44 & 102 & 49 & 31 & 215 & 342 & 109 & 43 & 24.35 & 0.000 \\
\hline \multirow[t]{2}{*}{ Total of PSQI } & \multicolumn{4}{|l|}{ Abuser } & \multicolumn{4}{|l|}{ Non-abuser } & $T$ test & $P$ value \\
\hline & \multicolumn{2}{|l|}{ Mean } & \multicolumn{2}{|l|}{ SD } & \multicolumn{2}{|l|}{ Mean } & \multicolumn{2}{|l|}{ SD } & & \\
\hline Sedatives & \multicolumn{2}{|l|}{12.33} & \multicolumn{2}{|l|}{4.235} & \multicolumn{2}{|l|}{9.15} & \multicolumn{2}{|l|}{4.317} & 7.343 & 0.000 \\
\hline Inhalants & \multicolumn{2}{|l|}{11.45} & \multicolumn{2}{|l|}{4.368} & \multicolumn{2}{|l|}{9.16} & \multicolumn{2}{|l|}{4.344} & 5.951 & 0.000 \\
\hline Cigarettes & \multicolumn{2}{|l|}{11.59} & \multicolumn{2}{|l|}{4.926} & \multicolumn{2}{|l|}{9.30} & \multicolumn{2}{|l|}{4.308} & 4.861 & 0.000 \\
\hline Narghile & \multicolumn{2}{|l|}{12.51} & \multicolumn{2}{|l|}{4.559} & \multicolumn{2}{|l|}{9.42} & \multicolumn{2}{|l|}{4.384} & 4.088 & 0.000 \\
\hline Hookah & \multicolumn{2}{|l|}{11.60} & \multicolumn{2}{|l|}{4.994} & \multicolumn{2}{|l|}{9.47} & \multicolumn{2}{|l|}{4.394} & 2.601 & 0.009 \\
\hline Chewing tobacco & \multicolumn{2}{|l|}{11.06} & \multicolumn{2}{|l|}{5.119} & 9.45 & & 4.369 & & 2.579 & 0.010 \\
\hline Energy drinks & 12.18 & & 5.305 & & 9.29 & & 4.257 & & 5.663 & 0.000 \\
\hline Soft drinks & 11.01 & & 4.581 & & 9.07 & & 4.275 & & 5.836 & 0.000 \\
\hline
\end{tabular}

where the percentage of students who used drugs ranged between 1.4 and $4.1 \%$.

The results of the current study revealed a variation in the prevalence rates of smoking among university students in Yemen and Saudi Arabia. The percentage of Yemeni students who smoked cigarettes was significantly higher than that of Saudi students who smoked cigarettes, while prevalence rates were close in both countries in terms of smoking hookah and shisha and chewing tobacco. With respect to the misuse of sedatives, inhalers, energy drinks, and soft drinks, the prevalence was high among Saudi students, with significant differences.

The researcher believes that cultural factors play an important role in creating the difference between students of both countries in terms of smoking and substance abuse, as most Yemeni smokers prefer to use tobacco while using khat, while Saudis prefer to consume soft drinks with meals. However, what is striking about these results is the high rate of abuse of inhalants and sedatives among the participants in this study. These results indicate that much effort must be made to combat the spread of psychotropic substances among university students in both countries.

Some previous studies pointed to low prevalence rates. For example, the percentage of students who misused sedatives was 3.4\% [28]. This percentage increased to $48 \%$ [27], while Ghandur, Sayed, and Martins [29] found that $15.1 \%$ of university students use sedatives. Osman et al. [2] reported a high prevalence of substance abuse (31\%) among university students. According to the results of the current study, the prevalence of poor sleep quality among the participants was high and the differences between the two countries were not significant. Low sleep quality may be attributed to the fact that some university students need more time to complete their tasks and assignments, so they use part of the time allocated to sleep to complete these tasks. This was confirmed by studies that indicated a low quality of sleep among college students [30-34]. Although the differences between Yemeni and Saudi students in terms of quality of sleep were not significant, other studies-for example, Peltzer and Pengpid [35] found differences between countries in terms of the prevalence of sleep disorders among university students.

There is evidence of a high prevalence of sleep disorders and poor sleep quality among university students [30-34, 36]. Peltzer and Pengpid [35] conducted a study of 20,222 undergraduate students from 26 countries in Asia, Africa, and the Americas and found that $10.4 \%$ of students had severe sleep problems, which were associated with tobacco use and poor academic performance, and that the prevalence of sleep problems varied from one country to another.

Our results indicate that poor sleep quality had an effect on the level of drug use among university students. According to Table 4, there is a significant relationship between sleep quality and drug use. A high score on the DAST-10 was offset by a decrease in sleep quality. It is as if poor sleep quality is an etiological factor of drug 
use, especially because students who do not use drugs had a high quality of sleep. The relationship between the overall PSQI score and drug use was significant; when the level of drug use rises, the overall PSQI score increases, which means that drug users have poor sleep quality more often than non-users do. The relationship between sleep quality, overall PSQI score, and substance abuse was also significant. Sleep quality was poor and the overall PSQI score was high in students who misused sedatives, inhalants, tobacco, energy drinks, or soft drinks. On the other hand, non-users of these substances enjoyed good sleep quality and had low overall PSQI scores.

These results complement those of previous studies that found a significant relationship between poor quality of sleep and drug use or substance abuse [37-42]. For example, Alamir et al. [41] found a significant relationship between misuse of medicinal drugs (non-medicinal use of drugs, substance abuse, and pain relievers) and poor sleep quality in university students. Goodhines et al. [42] reported a high prevalence of substance abuse among university students, and substance abuse was associated with poor sleep quality and insomnia. Some university students reported a decrease in the amount and quality of sleep on days when they consumed alcohol or energy drinks [40]. The relationship was significant between increased alcohol intake, sleep disturbances, and sleep quality [42], while poor sleep quality predicts the consequences of alcohol use among university students [38, 43]. Sleep quality decreased with increased alcohol or cigarette use by students [39]. Poor sleep quality was associated with cigarette smoking, while the prevalence of sleep disturbances among smokers was high compared to that of non-smokers [44]. There were also significant relationships between smoking and poor sleep quality, sleep disturbances, increased use of sleep medications, and daytime sleepiness [21].

Afandi et al. [45] found that $67.2 \%$ of university students in the United Arab Emirates suffer from a lack of sleep, while $75 \%$ of smokers have poor sleep quality. In a study with a large sample (2230) of university students, it was found that $52.7 \%$ had poor sleep quality and that cigarette smoking and chewing khat were significantly associated with poor sleep efficiency and increased use of sleep medications [46].

With regard to poor sleep quality and its relationship to drug and substance abuse, studies have indicated a relationship between the use of over-the-counter psychological stimulants and poor sleep quality among university students, who suffered from sleep disturbances and, often, got poorer ratings on sleep quality tests as compared to students who do not use these stimulants [37, 41]. Other reports have also shown that people who suffer from sleep disorders without having substance use disorders will misuse substances in the future and that most people who suffer from substance addiction also suffer from sleep disorders $[12,47]$.

In contrast, other studies did not find significant differences between smokers and non-smokers in terms of sleep quality $[48,49]$. It appears clear from the results of the current study that the poor quality of sleep is associated with drug use and substance abuse among university students in Yemen and Saudi Arabia. This subject needs more attention from researchers and decisionmakers in both countries.

\section{Conclusions}

Poor sleep quality is significantly associated with drug use and substance abuse and it is important to recognize the factors affecting drug and substance abuse among university students. A significant contribution can be made toward the protection of university students by guaranteeing that psychological interventions for highrisk groups are planned in advance.

\section{Limitations}

The results of the current study reflect the subjective estimates of drug use and substance abuse, and its relationship to sleep quality from the viewpoint of university students in Yemen and Saudi Arabia. The study relied on a self-assessment method based on questionnaires and psychological measures, and drug addiction has not been clinically tested in a psychiatric setting.

\section{Acknowledgements \\ I am grateful to Professor Dr. Kay M. Mach for proofreading and editing this article.}

Author's contributions

The author(s) read and approved the final manuscript.

\section{Funding}

Not applicable

\section{Availability of data and materials}

Available on reasonable request.

\begin{abstract}
Ethics approval and consent to participate
The study was conducted following the principles of the Declaration of Helsinki. Study materials and procedures were approved by the Aden University in Yemen (Ref 201/3/311) and King Khalid University in Saudi Arabia (Number 28423). All participants gave informed written consent. Students were informed that participation was completely voluntary and that the answer to the questionnaire was considered written express consent.
\end{abstract}

Consent for publication

Not applicable

Competing interests

Not applicable 
Received: 14 August 2020 Accepted: 27 October 2020 Published online: 23 November 2020

\section{References}

1. Gerra G, Zaimovic A, Rizzi O, Timpano M, Zambelli U (1999) Substance abuse among secondary-school students and its relationship with social coping and temperament. Bulletin on Narcotics LI 1 \& 2: 75-96 Retrieved from https://www.unodc.org/unodc/en/data-and-analysis/bulletin/bulletin_1 999-01-01_1.html Accessed 18 Dec 2019.

2. Osman T, Victor C, Abdulmoneim A, Mohammed H, Abdalla F, Ahmed A, Ali A, Mohammed M (2016) Epidemiology of substance use among university students in Sudan. J Addict 2476164:1-8. https://doi.org/10.1155/2016/ 2476164

3. Nemati Z, Matlabi H (2017) Assessing behavioral patterns of Internet addiction and drug abuse among high school students. Psychol Res Behav Manag 10:39-45. https://doi.org/10.2147/PRBM.S123224

4. Rabie M, Shaker NM, Gaber El-Habiby M, Ismail D, El-Gaafary M, Lotfy A, Sabry N, Khafagy W, Muscat R (2020) Prevalence updates of substance use among Egyptian adolescents. Middle East Curr Psychiatry 27:4. https://doi. org/10.1186/s43045-019-0013-8

5. Al-Hakim I (2007) Yemen: drug crossing gateway to the region. Mareb Press newspaper. https://marebpress.net/articles.php?id = 1593 (accessed 10 Dec 2019)

6. Fernandez-Mendoza J, Vgontzas AN (2013) Insomnia and its impact on physical and mental health. Curr Psychiatry Rep 15(12):418. https://doi.org/ 10.1007/s11920-013-0418-8

7. Li L, Wu C, Gan Y, Qu X, Lu Z (2016) Insomnia and the risk of depression: a meta-analysis of prospective cohort studies. BMC Psychiatry 16(1):375. https://doi.org/10.1186/s12888-016-1075-3 PMCID: PMC5097837

8. Ibrahim HA, Mahmud S, Abubakar A, Harazimi CA, Abdulkadir S (2016) Effect of drug abuse among youth and its impact on learning. IOSR J Pharm Biol Sci (IOSR-JPBS) 11(1):14-17. https://doi.org/10.9790/3008-11131417

9. Henry KL (2010) Academic achievement and adolescent drug use: an examination of reciprocal effects and correlated growth trajectories. J Sch Health 80(1):38-43. https://doi.org/10.1111/j.1746-1561.2009.00455x

10. Angarita GA, Emadi N, Hodges S, Morgan PT (2016) Sleep abnormalities associated with alcohol, cannabis, cocaine, and opiate use: a comprehensive review. Addict Sci Clin Pract 11:19. https://doi.org/10.1186/s13722-016-00567

11. Dunn KE, Finan PH, Andrew Tompkins D, Strain EC (2018) Frequency and correlates of sleep disturbance in methadone and buprenorphinemaintained patients. Addict Behav 76:8-14. https://doi.org/10.1016/j.addbeh. 2017.07.016

12. Khurshid KA (2018) Relationship between sleep disturbances and addiction. Mental Health Addict Res 3(3):1-4. doi: 10.15761/MHAR.1000162.

13. Angarita GA, Canavan SV, Forselius E, Bessette A, Pittman B, Morgan PT (2014) Abstinence-related changes in sleep during treatment for cocaine dependence. Drug and Alcohol Dependent 134:343-347. https://doi.org/10. 1016/j.drugalcdep.2013.11.007

14. Valentino RJ, Volkow ND (2020) Drugs, sleep, and the addicted brain. Neuropsychopharmacology 45:3-5 doi.org/10.1038/s41386-019-0465-X

15. Chakravorty S, Vandrey RG, He S, Stein MD (2018) Sleep management among patients with substance use disorders. Med Clin North Am 102(4): 733-743. https://doi.org/10.1016/j.mcna.2018.02.012

16. Blumenthal H, Taylor DJ, Cloutier RM, Baxley C, Lasslett H (2019) The links between social anxiety disorder, insomnia symptoms, and alcohol use disorders: findings from a large sample of adolescents in the United States. Behavior Therapy 50(1):50-59. https://doi.org/10.1016/j.beth.2018.03.010

17. Koob GF, Colrain IM (2020) Alcohol use disorder and sleep disturbances: a feed-forward allostatic framework. Neuropsychopharmacology 45:141-165. https://doi.org/10.1038/s41386-019-0446-0

18. Kaplan KA, McQuaid J, Batki SL, Rosenlicht N (2014) Behavioral treatment of insomnia in early recovery. J Addict Med 8(6):395-398. https://doi.org/10. 1097/ADM.0000000000000058

19. Sharkey KM, Kurth ME, Anderson BJ, Corso RP, Millman RP, Stein MD (2011) Assessing sleep in opioid dependence: a comparison of subjective ratings, sleep diaries, and home polysomnography in methadone maintenance patients. Drug and alcohol dependence 113(2-3):245-248. https://doi.org/10. 1016/j.drugalcdep.2010.08.007

20. Trksak GH, Bracken BK, Jensen JE, Plante DT, Penetar DM, Tartarini WL, Lukas SE (2013) Effects of sleep deprivation on brain bioenergetics, sleep, and cognitive performance in cocaine-dependent individuals. Sci World J 947879. https://doi.org/10.1155/2013/947879

21. Ogeil RP, Phillips JG (2015) Commonly used stimulants: sleep problems, dependence and psychological distress. Drug Alcohol Depend 153:145-151. https://doi.org/10.1016/j.drugalcdep.2015.05.036

22. Madruga CS, Paim TL, Palhares HN, Miguel AC, Massaro LTS, Caetano R, Laranjeira RR (2019) Prevalence of and pathways to benzodiazepine use in Brazil: the role of depression, sleep, and sedentary lifestyle. Braz J Psychiat 41(1):44-50. https://doi.org/10.1590/1516-4446-2018-0088

23. Hasler BP, Smith L, Cousins JC, Bootzin RR (2012) Circadian rhythms, sleep, and substance abuse. Sleep Med Rev 16(1):67-81. https://doi.org/10.1016/j. smrv.2011.03.004

24. KKU (2018) King Khalid University Strategic Plan 2018-2020. https://web. archive.org/web/20180820035942if_/http://www.kku.edu.sa:80/sites/default/ files/general_files/pdf/Stratigic\%20plan.compressed.pdf.

25. Skinner HA (1982) The drug abuse screening test. Addict Behav 7(4):363-371

26. Buysse DJ, Reynolds CF III, Monk TH, Berman SR, Kupfer DJ (1989) The Pittsburgh Sleep Quality Index: a new instrument for psychiatric practice and research. J Psychiatr Res 28(2):193-213 Retrieved from http://www. sleep.pitt.edu/content.asp?id=1484\&subid $=2316$

27. Brandt SA, Taverna EC, Hollock RM (2014) A survey of nonmedical use of tranquilizers, stimulants, and pain relievers among college students: Patterns of use among users and factors related to abstinence in non-users. Drug and alcohol Dependence 143:272-276. https://doi.org/10.1016/j.drugalcdep.2014.07.034

28. Kounenou K (2011) Drug use by Greek university students and preventive actions. Procedia Soc Behav Sci 15:456-460. https://doi.org/10.1016/j.sbspro. 2011.03.121

29. Ghandur LS, El Sayed DS, Martins SS (2012) Prevalence and patterns of commonly abused psychoactive prescription drugs in a sample of university students from Lebanon: an opportunity for cross-cultural comparisons. Drug and Alcohol Dependence 121(1-2):110-117. https://doi.org/10.1016/j. drugalcdep.2011.08.021

30. Lemma S, Gelaye B, Berhane Y, Worku A, Williams MA (2012a) Sleep quality and its psychological correlates among university students in Ethiopia: a cross-sectional study. BMC Psychiatry 12:237. https://doi.org/10.1186/1471244X-12-237

31. Merdad RA, Merdad LA, Nassif RA, El-Derwi D, Wali SO (2014) Sleep habits in adolescents of Saudi Arabia; distinct patterns and extreme sleep schedules. Sleep Med 15(11):1370-1378. https://doi.org/10.1016/j.sleep.2014.06.008

32. Alsaggaf A, Wali O, Merdad R, Merdad A (2016) Sleep quantity, quality, and insomnia symptoms of medical students during clinical years: relationship with stress and academic performance. Saudi Med J 37(2):173-182. https:// doi.org/10.15537/smj.2016.2.14288

33. Jain A, Verma S (2016) Prevalence of sleep disorders among college students: a clinical study. J Adv Med Dent Sci Res 4(6):103-106. https://doi. org/10.21276/jamdsr.2016.4.6.23

34. Schlarb AA, Friedrich A, Claßen M (2017) Sleep problems in university students - an intervention. Neuropsychiatr Dis Treat 13:1989-2001. https:// doi.org/10.2147/NDT.S142067

35. Peltzer K, Pengpid S (2015) Nocturnal sleep problems among university students from 26 countries. Sleep Breath 19(2):99-508. https://doi.org/10. 1007/s11325-014-1036-3

36. Gaultney J (2010) The prevalence of sleep disorders in college students: impact on academic performance. J Am Coll Health 59(2):91-97. https://doi. org/10.1080/07448481.2010.483708

37. Clegg-Kraynok MM, McBean AL, Montgomery-Downs HE (2011) Sleep quality and characteristics of college students who use prescription psychostimulants nonmedically. Sleep Med 12(6):598-602. https://doi.org/ 10.1016/j.sleep.2011.01.012

38. Kenney SR, Paves AP, Grimaldi AM, LaBrie JW (2014) Sleep quality and alcohol risk in college students: examining the moderating effects of drinking motives. J Am Coll Health 62(5):301-308. https://doi.org/10.1080/ 07448481.2014 .897953

39. Valerio TD, Kim MJ, Sexton-Radek K (2016) Association of stress, general health, and alcohol use with poor sleep quality among U.S. college students. Am J Health Educ 47(1):17-23. https://doi.org/10.1080/19325037.2015.1111173

40. Patrick ME, Griffin J, Huntley ED, Maggs JL (2018) Energy drinks and binge drinking predict college students' sleep quantity, quality, and tiredness. Behav Sleep Med 16(1):92-105. https://doi.org/10.1080/15402002.2016.1173554

41. Alamir YA, Zullig KJ, Wen S, Montgomery-Downs H, Kristjansson AL, Misra R, Zhang J (2019) Association between nonmedical use of prescription drugs 
and sleep quality in a large college student sample. Behav Sleep Med 17(4): 70-480. https://doi.org/10.1080/15402002.2017.1403325

42. Goodhines PA, Gellis LA, Kim J, Fucito LM, Park A (2019) Self-medication for sleep in college students: concurrent and prospective associations with sleep and alcohol behavior. Behav Sleep Med 17(3):327-341. https://doi.org/ 10.1080/15402002.2017.1357119

43. Kenney SR, LaBrie JW, Hummer JF, Pham AT (2012) Global sleep quality as a moderator of alcohol consumption and consequences in college students. Addict Behav 37(4):507-512. https://doi.org/10.1016/j.addbeh.2012.01.006

44. Cohrs S, Rodenbeck A, Riemann D, Szagun B, Brinkmeyer JA et al (2014) Sleep in smokers. Addict Biol 19:486-496. https://doi.org/10.1111/j.13691600.2012.00487.x

45. Afandi O, Hawi H, Mohammed L, Salim F, Hameed AK, Shaikh RB, Al Sharbatti S, Khan FA (2013) Sleep quality among university students: evaluating the impact of smoking, social media use, and energy drink consumption on sleep quality and anxiety. Inquiries J/Student Pulse 5(06):23 Retrieved from http://www.inquiriesjournal.com/a?id=738

46. Lemma S, Patel SV, Tarekegn YA, Tadesse MG, Berhane Y, Gelaye B, Williams MA (2012) The epidemiology of sleep quality, sleep patterns, consumption of caffeinated beverages, and khat use among Ethiopian college students. Sleep Disord 583510. https://doi.org/10.1155/2012/583510

47. Mahfoud Y, Talih F, Streem D, Budur K (2009) Sleep disorders in substance abusers: how common are they? Psychiatry (Edgmont) 6(9):38-42 PMID: 19855859; PMCID: PMC2766287

48. Cohen A, Colodner R, Masalha R, Haimov I (2019) The relationship between tobacco smoking, cortisol secretion, and sleep continuity. Subst Use Misuse 54(10):1705-1714. https://doi.org/10.1080/10826084.2019.1608250

49. Cohen A, Abu NB, Haimov I (2020) The interplay between tobacco dependence and sleep quality among young adults. Behav Sleep Med 18(2):163-176. https://doi.org/10.1080/15402002.2018.1546707

\section{Publisher's Note}

Springer Nature remains neutral with regard to jurisdictional claims in published maps and institutional affiliations.

\section{Submit your manuscript to a SpringerOpen ${ }^{\circ}$ journal and benefit from:}

- Convenient online submission

- Rigorous peer review

- Open access: articles freely available online

- High visibility within the field

- Retaining the copyright to your article

Submit your next manuscript at $\boldsymbol{\nabla}$ springeropen.com 